\title{
AMPICILINA K EM DOSE ÚNICA, POR VIA ORAL, NO TRATAMENTO DA GONORRÉIA
}

\begin{abstract}
Barros, J. M. de; Menezes, J. P. de \& Bassoi, O. N. - Ampicilina $\mathrm{K}$ em dose única, por via oral, no tratamento da gonorréia, Rev. Saúde públ., S. Paulo, 4:31-34, jun. 1970.

RESUMo - Foram tratados 70 pacientes do sexo masculino portadores de uretrite gonocócica aguda com $3,0 \mathrm{~g}$ de Ampicilina $K$ por via oral, em dose única. $\mathrm{Em} \mathbf{8 7 , 1 \%}$ dos casos houve desaparecimento da secreção uretràl; na grande maioria dos casos entre 24 e 72 horas. Considerados mais 3 casos em que houve persistência da secreção pós tratamento, mas com ausência de gonococos aos exames bacteriológicos (cura bacteriológica) o sucesso terapêutico pode ser elevado para $91,4 \%$.
\end{abstract}

Com a descoberta da penicilina, as moléstias venéreas tiveram considerável declínio, não mais sendo consideradas problemas de saúde pública na maioria dos países. No entanto, por volta de 1958, começaram a aparecer dados sôbre o recrudescimento da sífilis e gonorréia. Em 1959, a Organização Mundial da Saúde ${ }^{1}$ notificava aumento destas doenças em 15 países da América e Europa.

Em 1962, a Comissão de Peritos em Infecções Gonocócicas da OMS ${ }^{1}$ mostrou a grande dificuldade em obter dados de incidência da gonorréia, mas julgava a situação real como sendo cem vêzes maior do que a notificada e estimava o número de casos novos em mais de 60 milhões.
Outra observação dos epidemiologistas foi de que a gonorréia estava ocorrendo em grupos de jovens de 15 a 19 anos de idade.

Por outro lado, tem-se verificado que um tratamento que se mostrava eficaz na cura da gonorréia há 20 anos atrás, com 100 mil unidades de penicilina procaína, hoje necessita dose dez vêzes maior, pelo menos. Além disso, mais e mais casos de resistência e reações a êsse antibiótico vêm sendo registrados; daí a necessidade de outros medicamentos para o tratamento da gonorréia.

O presente estudo mostra o resultado da pesquisa de um nôvo antibiótico Ampicilina $\mathrm{K}$ - sal potássico do ácido

Recebido para publicaç̃o em 11-3-1970.

(1) Do Departamento de Epidemiologia da Faculdade de Saúde Pública da USP - São Paulo, S.P., Brasil.

(2) Da Secretaria de Higiene da Prefeitura Municipal de São Paulo - Brasil.

(3) Da Faculdade de Medicina da USP - São Paulo, S.P., Brasil. 
B̧ARROS, J. M. de; MENEZES, J. P. de \& BASSOI, O. N. - Ampicilina $\mathrm{K}$ em dose única, por via oral, no tratamento da gonorréia. Rev. Saúde pübl., S. Paulo, 4:31-34, jun. 1970.

6-D (- $\alpha$ amino-fenil acetamido penicilânico) no tratamento da uretrite gonocócica em esquema rápido, de única dose.

A Ampicilina $\mathrm{K}$ é um derivado do ácido 6-amino-penicilânico de largo espectro, com ação antibiótica e atividade antibacteriana Gram-positiva e Gram-negativa, já observada "in vitro" e "in vivo". É ab. sorvida pelas vias oral e parenteral e eliminada, em grande proporção, pela urina.

Menezes e Ximenes (1) (1969) verificaram que a Ampicilina $K$, na dose de 3,0 g por via oral, apresentava níveis séricos superiores a $15,0 \mathrm{mcg} / \mathrm{ml} 2$ horas após a administração. A média de re. cuperação urinária, no período de 12 ho. ras, foi superior a $50 \%$. da USP. 0 medicamento era tomado na presença do médico ou seu assistente.

\section{Tempo de moléstia:}

Foram escolhidos para observação portadores de uretrite com duração inferior a 15 dias. Cêrca de $80 \%$ dos pacientes contava sintomatologia datando de menos de 8 dias.

\section{Tratamento anterior:}

De um modo geral, procurou-se incluir no estudo apenas casos virgens de tratamento específico. No entanto, alguns pacientes que haviam recebido algum antibiótico em dose considerada insuficiente

TABELA 1

Niveis de Ampicilina no sôro até 12 horas após a administração

\begin{tabular}{|c|c|c|c|c|c|c|c|}
\hline \multirow{2}{*}{$\begin{array}{r}\text { Tempo } \\
\text { hs }\end{array}$} & \multirow[b]{2}{*}{$1 / 2$} & \multirow[b]{2}{*}{1} & \multirow[b]{2}{*}{2} & \multirow[b]{2}{*}{3} & \multirow[b]{2}{*}{5} & \multirow[b]{2}{*}{8} & \multirow[b]{2}{*}{12} \\
\hline & & & & & & & \\
\hline Ampicilina via oral & 5,78 & 13,02 & 15,79 & 11,21 & 3,04 & 0,57 & 0,11 \\
\hline
\end{tabular}

Pacientes:

Setenta pacientes adultos foram estudados; quase todos eram solteiros, e os poucos casados incluídos no grupo estavam separados das espôsas. Com isso, procurava-se evitar re-infecções que prejudicassem o estudo. A idade dos paciente variava de 16 a 45 anos, mas a grande maioria estava no grupo de 20 a 30 anos de jdade.

Os pacientes estavam sob o contrôle do médico do Serviço de Doenças Venéreas do Centro de Saúde "Geraldo de Paula Souza" da Faculdade de Saúde Pública foram incluídos no estudo porque apresentavam corrimento uretral com a presença de gonococos nos esfregaços e culturas. E interessante notar que o antibiótiro mais utilizado foi a tetraciclina.

\section{Critério para o diagnóstico:}

De todos os pacientes foi colhido material de secreção uretral para exame em esfregaço e cultura. $O$ esfregaço era corado pelo método de Gram e a cultura feita em meios com sangue e chocolate. Só foram incluídos no estudo casos onde foi positivada a presença de $N$. gonorrhoeae.

(1) Trabalho elaborado no Departamento de Microbiologia Clínica da Divisão Médica da Laborterápica Bristol S/A - Dados inéditos. 
BARROS, J. M. de; MENEZES, J. P. de \& BASSOT, O. N. - Ampicilina $\mathbf{K}$ em dose única, por via oral, no tratamento da gonorréia. Rev. Saúde públ., S. Paulo, 4:31-34, jun. 1970.

\section{Contrôle dós pacientes:}

0 período de observação foi de 15 dias. Os pacientes eram examinados no $3 .^{\circ} \mathrm{e}$ 15. dias após o tratamento. Durante o período de observação era colhido material para exame em esfregaço e cultura de qualquer secreção uretral apresentada pelo paciente.

\section{Critério de cura:}

Foram considerados "curados clìnicamente" os pacientes em que o corrimento cessou após a terapêtica e não era possível obter-se secreção através de expressão da urectra. Em alguns pacientes (cêrca de 4\%) houve persistência da secreção uretral, em geral muco-hialina e escassa, sem que pudesse ser comprovada a presença de gonococos em exames de esfregaço e cultura. Via de regra, os germes encontrados eram estafilacocos, estrep. tococos e micrococos. Esses casos podem ser considerados como "cura bacteriológica".

Os casos de "insucesso terapêutico" foram aquêles que, durante o período de observação, recidivaram ou continuaram com secreção uretral, onde foram demonstrados gonococos intra ou extra-celulares em exames de esfregaço e $N$. gonorrhoeae na cultura. E interessante notar que os casos de recidiva foram observados até o quinto dia depois do tratamento.

Os casos curados com uma segunda dose do medicamento, após serem considerados "insucesso" com a primeira dose, não foram incluídos no presente estudo.

\section{Tratamento:}

Foram observados 70 pacientes do sexo masculino, acusando uretrite gonocócica, comprovada pela presença de $N$. gonorrhoeae em exames de esfregaço e cultura. A grande maioria dos casos $(80 \%)$ apresentava o corrimento há menos de 8 dias.

Os pacientes receberam $3,0 \mathrm{~g}$ de Ampicilina potássica, por via oral sob forma de cápsulas de 0,500 ou $0,250 \mathrm{~g}$ ca- da uma. 0 medicamento era tomado na frente do médico ou de seu assistente.

Não foram registrados casos de intolerância ao medicamento.

\section{Resultados do tratamento: (Ver Anexo)}

1. Cura clínica:

O corrimento cessou em 61 pacientes $(87,1 \%$ dos casos) em 24 , horas $(11,4 \%), 48$ horas $(65,7 \%)$, 72 horas $(12,9 \%)$ ou mais de 72 horas $(1,4 \%)$.

2. Cura bacteriológica:

Em 3 casos $(4,3 \%)$ continuou um discreto corrimento muco-hialino ou gota pela manhã, sem que pudesse ser comprovada a presença de $N$. gonorrhoeae em exames de esfregaço ou cultura. Outros germes foram identificados, tais como está filococos, estreptococos e micrococos sp.

3. Insucesso terapêutico:

Em 6 casos $(8,6 \%)$ o corrimento continuou ou recidivou poucos dias após, sendo comprovada a presença de $N$. gonorrhoeae em exames de esfregaço ou cultura.

Se considerarmos os casos de cura clínica e bacteriológica, teremos $91,4 \%$ de bom êxito para $8,6 \%$ de insucesso terapêutico.

Barros, J. M. de; Menezes, J. P. de \& Bassor, O. N. - [One single oral dose of Ampicillin $\mathrm{K}$ in the tratment of gonorrhea]. Rev. Saride públ., S. Paulo, 4:31-34, jun. 1970.

SumMary - Seventy male patients with acute gonorrhea with $3.0 \mathrm{~g}$ of Ampicillin $K$ in a single oral dose were treated. Discharge disappeared in $87.1 \%$ of cases, in an average of 24-72 hours (clinical cure). Three cases $(4.3 \%)$ showed a light mucous hialine discharge with no $N$. gonorrhoeae (bacteriological cure). Urethral discharge persisted in 6 patients $(8.6 \%)$ with $N$. gonorhoeae in smears and culture (Failure). Clinical and/or bacteriological cure were observed in 64 patients $(91.4 \%)$. 
BARROS, J. M. de; MENEZES, J. P. de \& BASSOI, O. N. - Ampicilina $K$ em dose única, por via oral, no tratamento da gonorréia. Rev. Saúde públ., S. Paulo, 4:31-34, jun. 1970.

\section{REFERENCIA BIBLIOGRAFICA}

1. ORGANIZACION MUNDIAL DE LA SALUD. Comité de Expertos en Infecciones Gonococicas - Primer informe. Ginebıa, 1963. (OMS - Ser. inf. técn., 262).

\section{BIBLIOGRAFIA CONSULTADA}

1. BARROS, J. M. de; BASSOI, O. N. \& MENEZES, J. P. de - Tratamento da gonorréia com Hetacilina. In: SIMPoSro SOBRE PENICILINAS SEMI-SINTETICAS E NOVOS ANTIBIótICOS, São Paulo, 1967. Anais. São Paulo, 1968. p. 110-17.

2. BUNN, P. A.; MILICICH, S. \& LUNN, J. S. - Pharmacological properties of $\mathrm{He}$ tacillin in the human. Antimicrob Agents Chemother. - 1965. p. 947-50, 1966.

3. DUARTE, C. R.; FLORES, E. J. \& FERRER, J. A. P. - Estudo comparativo do efeito terapêutico de um regime de doses úricas de Hetacilina e Ampicilina na u' atrite gonocócica. O Hospital, 75: 979-86, mar. 1969.

4. FERRER, J. A. P.; FLORES, E. J. \& DUARTE, C. R. - Avaliação clínica da Hetacilina por via oral em 180 pacientes com uretrite gonocócica. Rev. bras. Pesq. med. biol., 2:135-40, mar./abr. 1969.

5. FLORES, E. J.; FERRER, J. A. P. \& DUARTE, C. R. - Uso clínico de um penicinato (Hetacilina-BL p. 804) por via intramuscular no tratamento da blenorragia. Estudo de 50 pacientes. Rev. bras. Pesq. med. biol., 2:141-42, 1969.

6. TUANO, S. B. et al. - Comparative blood levels of Hetacillin, Ampicillin and $\mathrm{Pe}$ nicillin G. New Eng. J. Med., 275:635-39, Sept. 1966.

$A \mathrm{~N} E \mathrm{X} O$

Distribuição e análise dos dados

I. Idade:

\begin{tabular}{lrr} 
anos & $n .^{\circ}$ & $\%$ \\
$16 \mid-20$ & 12 & 17,1 \\
$20 \mid-30$ & 46 & 65,7 \\
$30 \mid-40$ & 9 & 12,9 \\
40 e mais & 3 & 4,3 \\
\hline total & 70 & 100,0
\end{tabular}

II. Tempo de molestia:

\begin{tabular}{lrc} 
dias & $n .^{\circ}$ & $\%$ \\
menos de 8 & 56 & 80,0 \\
8 a 15 & 13 & 18,6 \\
mais de 15 & 1 & 1,4 \\
\hline total & $\overline{70}$ & 100,0
\end{tabular}

III. Tratamento anterior:

\begin{tabular}{lcc} 
tratamento & $n 0^{\circ}$ & $\%$ \\
sem tratamento anterior & 53 & 75,7 \\
$\begin{array}{l}\text { com algum tratamento an- } \\
\text { terior }\end{array}$ & 17 & 24,3 \\
\hline total & - & 100,0
\end{tabular}

IV. Tempo para o desaparecimento do corrimento:

\begin{tabular}{lrr} 
horas & $n \cdot 0$ & $\%$ \\
24 & 8 & 11,4 \\
48 & .46 & 65,7 \\
72 & 9 & 12,9 \\
mais de 72 & 1 & 1,4 \\
não desapareceu & 6 & 8,6 \\
\hline total & - & 100,0
\end{tabular}

V. Resultado do tratamento:

\begin{tabular}{lrr} 
Cessou corrimento comple- & $n .^{\circ}$ & $\%$ \\
tamente (cura clínica) & 61 & 87,1 \\
$\begin{array}{l}\text { Continuou corrimento dis- } \\
\text { creto muco hialino sem }\end{array}$ & \\
$\begin{array}{l}\text { gonococos (cura bacte- } \\
\text { riológica) }\end{array}$ & 3 & 4,3 \\
$\begin{array}{l}\text { Continuou corrimento ou } \\
\text { recidivou, com gonococos }\end{array}$ & 6 & 8,6 \\
\hline total & $\overline{70}$ & $-100,0$
\end{tabular}

VI. Conclusano:

\begin{tabular}{lrr} 
Cura (clinica e bacterio- & $n . *$ & $\%$ \\
$\begin{array}{lrr}\text { lógica) } \\
\text { Insucesso terapêtico }\end{array}$ & 64 & 91,4 \\
\hline total & - & 8,6 \\
\cline { 2 - 3 } & 70 & 100,0
\end{tabular}

